\title{
Classification and SLA Studies of Passive Voice
}

\author{
Yuanying Wang \\ School of Foreign Languages, Qingdao University of Science and Technology, Qingdao 266061, China \\ Email: yywang789@yahoo.com.cn
}

\begin{abstract}
Passive voice has been one important and difficult part of grammar. This thesis focuses on Quirk's and Granger's definition and classification of passive voice and presents the historical views on the research of passive voice from the point of second language acquisition studies.
\end{abstract}

Index Terms - passive voice, classification, second language acquisition

\section{DEFinition AND CHARACTERISTICS OF PASSIVE Voice}

\section{A. $\quad$ Voice Defined}

Passive voice is not a derivative of active voice, which is the outcome of people's different meaning expression. Passive voice describes the whole process of certain event from the patient's point of view. It is a marked form of voice. There are three markers in passive voice, be, -ed and by, which has its meaning and significance respectively. Typical passive could be classified into two categories, passive with agent and passive without agent, or, agentive passive and non-agentive passive. In the agentive passive, the agent will not appear but will be implicit in the context.

\section{B. Characteristics of Passive Voice}

Characteristically English is a typical inflectional language, in which there are various inflectional variants. English belongs to explicit linguistic category, while Chinese has the open and implicit linguistic characteristics.

Voice is a grammatical category which makes it possible to view the action of a sentence in two ways (Quirk, et al, 1972, 801-811), without change in the facts reported:

(1) The butler murdered the detective.

(2) The detective was murdered by the butler.

Sentence (1) is in active voice and sentence (2) in passive voice.

The active-passive relation involves two grammatical 'levels': the verb phrase and the clause. In the verb phrase, the difference between the two voice categories is that the passive adds a form of the auxiliary and the past participle ( $-V e d)$ of the main verb.

At the clause level, passivization involves rearrangement of two clause elements and one addition. (A) The active subject becomes the passive agent, (B) the active object becomes the passive subject, and (C) the preposition by is introduced before the agent. The prepositional agent phrase of passive sentences is an optional sentence element. The process of active-passive transformation for monotransitive sentence with nominal object can be represented diagrammatically.

S

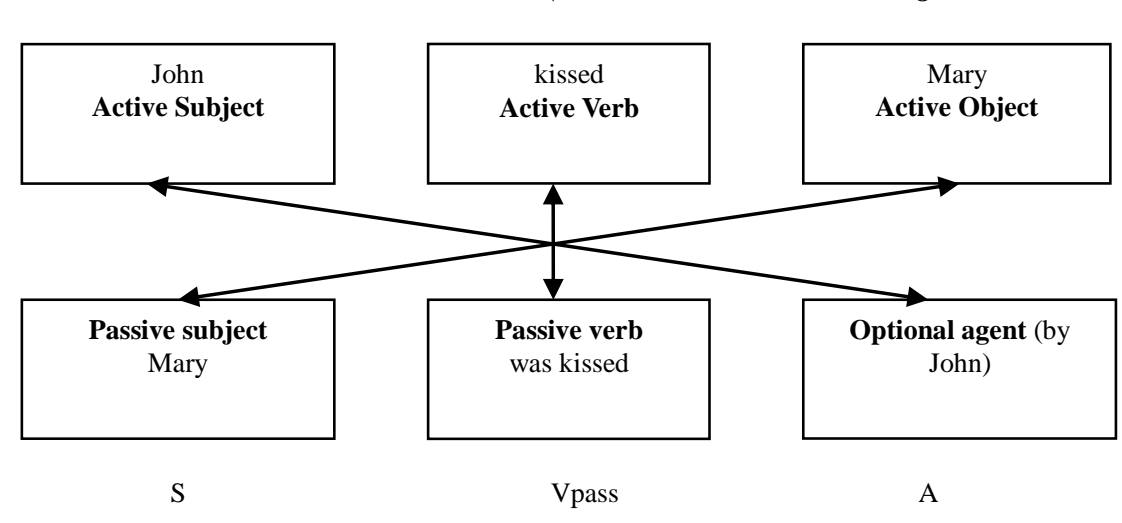

Figure 1 The active-passive relation

The prepositional agent phrase of passive sentence is an optional sentence element. Consequently, voice transformation can be expressed in this formula: 
Noun phrase $1+$ active verb phrase + noun phrase2

$\sim$ Noun phrase $2+$ passive verb phrase + (by noun phrase)

Although the structure of a sentence changes under voice transformation, its meaning remains the same. In John kissed Mary and Mary was kissed by John, John is the "performer of the action" in both voices. In the sentence structure, however, the active subject corresponds to the passive agent.

\section{Views About Classification of Passive Voice}

\section{A. Quirk's View about Classification of Passive Voice}

The passive construction has been classified in many different ways. Summarizing the discussion of the passive scale in the "A Grammar of Contemporary English" (1972), Quirk set up the following subcategories.

1. Agentive passives

Agentive passive involves with expressed agent and without expressed agent. Sentence (1) and (2) have a direct passive-active relation. The difference between the next two is that the former has a personal, the latter a non-personal agent:

(3) My father made this violin.

(4) The results hardly justify this conclusion.

With expressed agents:

(5) Coal has been replaced by oil.

This is a passive with two possible active transforms depending on the interpretation of the by-phrase.

(6) Oil has replaced coal.

(7) (People in many countries) have replaced coal by oil.

Sentence (6) is an active transform like (4) with a non-personal agent; (7) is an active transform where the by-phrase has been given an instrumental interpretation (by=with). Consequently an active subject must be supplied.

Without expressed agents:

(8) This difficulty can be avoided in several ways.

Sentence (8) exemplifies the most common type of passive, which has no expressed agent, or agentless passives.

2. Quasi-passives

(9) We are encouraged to go on with the project.

(10) John was interested in linguistics.

The passive sentences (9) and (10) represent a "mixed" class whose members have both verbal and adjectival properties. They are verbal in having active analogues:

(11) (The results) encourage us to go on with the project.

(12) Linguistics interested John.

3. Non-agentive passives/intensive active complement constructions

(13) The modern world becomes more highly industrialized and mechanized.

Sentence (13) has no active transform or possibility of agent addition, since no "performer" is conceived of. The participles have adjectival values: compare industrialized-industrial and mechanized-mechanical. Besides a number of such "resulting" verbs ending in -ize (organize, Americanized, etc), this class includes "existing" constructions, as in

(14) The house is already sold.

The corresponding active of which is not (15) but (16).

(15) (The agent) already sells the house.

(16) (The agent) has already sold the house.

In this case, voice transformation involves aspectual shift from present to present perfect.

While it is clear that (13) and (14) are not 'passive' in the sense of sentences, they still satisfy the formal passive requirement and, as in the case of (14), often have an "indirect" voice relationship. We will therefore call this class "non-agentive passive/intensive active complement constructions", recognizing that The house is already sold. It is related both to agentive passive The house has already been sold and to the intensive (active) complement construction.

(17) The house is already gone/ no longer available.

B. Quirk's Another Passive Scale (Quirk, et al, 1972, 266-231)

TABLE 1

QUIRK'S PASSIVE SCALE

\begin{tabular}{|c|c|c|c|c|}
\hline \multicolumn{5}{|c|}{ Quirk's passive scale } \\
\hline \multicolumn{2}{|c|}{$\begin{array}{l}\text { Central passive or true } \\
\text { passive }\end{array}$} & \multirow{2}{*}{$\begin{array}{l}\text { semi-passive or } \\
\text { mixed passive }\end{array}$} & \multicolumn{2}{|c|}{ Pseudo-passive } \\
\hline $\begin{array}{l}\text { With } \\
\text { agentive } \\
\text { phrase }\end{array}$ & $\begin{array}{l}\text { Without } \\
\text { agentive } \\
\text { phrase }\end{array}$ & & $\begin{array}{l}\text { With current copula verbs, e.g., be, } \\
\text { feel, look }\end{array}$ & $\begin{array}{c}\text { With resulting copula verbs, } \\
\text { e.g., } \\
\text { get, become, grow }\end{array}$ \\
\hline
\end{tabular}

\section{Granger's View}


Granger (1983:81-190) has concentrated on the be + past participle construction, and classified it into seven categories, namely, passives, adjectival pseudo-passives, verbal pseudo-passives, mixed be+ Ved combinations, usually passive category, peripheral combinations and stative combinations.

Examples (18)-(24) illustrate them respectively:

(18) That attitude was maintained by the government in the further nine days of debates in the Lords.

(19) Perhaps the tick is rather more complicated.

(20) She's been rather elusive as far as I'm concerned, so I don't really know her.

(21) I am amazed at the price of houses out here.

(22) I feel we're all faced with this problem.

(23) I'm fairly closely connected with that work.

(24) But I have these two houses that are built on to the next door's back garden sort of thing...

Granger's classification is in great detail. Actually the latter four categories are the borderline cases and they are very much related to, and sometimes can be put into the first category.

As a matter of fact, though they choose different terms, Granger's and Quirk, et al's classifications are more or less overlapped. For instance, Quirk, et al's central passives are the same as Granger's passives, semi-passives are to some extent equal to mixed be-Ved combinations. Pseudo-passives are divided into adjectival and verbal pseudo-passives in Granger's classification

\section{HistoriCAL VIEWS ON L2 USE OF PASSIVE VOICE CONSTRUCTION}

Second Language Acquisition researches on passive voice construction mainly originated from the late 1970s, when two influential notions were proposed and paved the way for studying passive construction from the perspective of SLA.

One remarkable notion is the distinction between topic-prominent and subject-prominent language suggested by Li and Thompson (1976). Li and Thompson divide languages into topic-prominent and subject-prominent: topic-prominent languages are those in which "the basic structure of sentences favours a description in which the grammatical relation topic-comment plays a major role", while subject-prominent languages are those in which "the basic structure of sentences favours a description in which the grammatical relation subject-predicate plays a major role" (Li \& Thompson 1976:459). And they observe that while the passive construction is common in subject-prominent languages, it is less productive in topic-prominent language; some do not have passives at all.

Another influential idea is Unaccusataive Hypothesis proposed by Perlmutter (1978) and updated by Burzio (1986). Perlmutter is the first to propose that there exit two distinct classes of intransitive verbs: one class is called unaccusative and the other unergative; while Burzio is the first to describe the two classes of intransitive verbs in framework where the sole argument of unergative verbs is an agent generated in subject position whereas that of unaccusative verbs is a theme or patient base generated in object position. Unaccusative Hypothesis discusses that syntactically unaccusative verbs "resemble other intransitive verbs in that they subcategorize for a single argument and that argument generally appears on the surface as the subject" (Yip, 1995:130); whereas semantically these verbs "describe changes of state and process that lack volitional control on the part of the subject" (Yip, 1995:130).

Yip (1995) draws her attention to Chinese-speaking learners even though all the 20 subjects in her experiment come from Taiwan rather than the Chinese mainland. Yip mainly observes how the Chinese EFL learners could clearly distinguish grammatical passive construction, pseudo-passives and ungrammatical passivization of unaccusative verbs by adopting the approach of grammaticality-judgment. Yip concludes that Chinese learners tend to undergenerate grammatical passives while they overextend the passivization to unaccusative verbs. According to Yip, "the pseudo-passive is a malformed passive" (Yip, 1995:99), this could be illustrated in the following sentences:

(55) New cars must keep inside.

(56) These sentences can analyze many ways.

(57) Erhu [Chinese violin] can play like this.(Yip, 1995:97)

Yip argues that the acceptance of pseudo-passives for Chinese learners lie in the confusion of the topic-prominence language (Chinese) and the subject-prominence language (English). In terms of the passive unaccusative, Yip first divides the unaccusative verbs into "unpaired verbs, which only occur as unaccusatives; and paired verbs, which have a transitive counterpart" (Yip, 1995:143). And she points out that the confusion of paired unaccusative verbs and transitive verbs leads to the over-passivization of unaccusatives and speculates from the learnablility perspective that internalized, inappropriate passives of paired unaccusatives would be harder to expunge than that of unpaired unaccusative.

Hirakawa $(1995,2001)$ investigates Japanese learners' knowledge of unaccusatives in English. Hirakawa elicits judgment of sentences with paired unaccusatives (melt, brake continue, dry, increase, spill), unpaired unaccusatives (appear, die, fall, arrive, happen, disappear), and transitive verbs (hit, cut, see, read, build, need). Japanese learners are predicted to behave in much the same way as the Chinese learners in Yip's research. Hirakawa attributed the phenomenon of the passive unaccusative to the negative transfer of native language.

Oshita (2000), based on his analysis of the 1993 version of the Longman learners' Corpus, also reports that similar errors are produced by L2 learners of different L1 backgrounds. He compares samples of passive errors with 
equivalents in the learners' L1 and concludes that the problem is not direct L1 transfer. He claims that the most plausible account of the passive unaccusative structure is regarded as an overt marker of NP movement, and an overgeneralization of the passive morphosyntax of the target language.

Montrul (1999) independently investigates acquisition of the semantics and morphosyntax of causatives and unaccusatives, and he reports that the same type of error also exists in Spanish L2 interlanguage.

Cai (2000) studies the Chinese ESL learners' knowledge of unaccusative verbs. Certainly, his study is inevitably concerned with the passive unaccusative. He finds that Chinese learners seldom produce ungrammatical passivization of unpaired unaccusatives but they can not perfectly judge the passivization of paired unaccusatives. And he attributes the passive paired unaccusatives to the proficiency of target language and the negative transfer of native language.

There has been a substantial body of comparative studies of English passive and its Chinese counterpart at home. However, they were almost exclusively focused on: 1) description of its syntactic features (Nancao 2003). 2) The essence of verbs in English passive voice (Tang Yanling, 2003). 3) comparative study between English and Chinese passive voice from the linguistic point of view or from a cognitive linguistic point of view (Gu Tingting 2003; Shen Wenan 2003; Zen Qing 2003; Xiong Xueliang \& Wang Zhijun 2001, 2003). The research on the acquisition of English passive by the Chinese learners is unfortunately lacking. To date, two studies (Chen Wanxia 2002; Wang Yunfeng 2004) in this field have been conducted. Chen Wanxia conducted a corpus-based research on the acquisition on English passive by Chinese learners. Based on Chinese learners English corpus (CLEU), she analyzed the errors by Chinese learners across several proficiency levels (senior high school students, non-English majors of intermediate and higher proficiency levels, English majors of intermediate and higher proficiency levels) and concluded all learners encountered the similar difficulties: the elaborate verb morphological change and under-use of English passive, which could be attributed to the poor grasp of verb usages and negative transfer of the mother tongue. The errors amounted to 44.9 percent and 32.1 percent out of total errors respectively. Some researchers attributed these errors to the negative morphological and syntactic transfer (Li \& Thompson 1976; Rutherford 1983; Yip 1995; Chen Wanxia 2002; Wang Yunfeng 2004). Wang's study was concerned with the learning process involved in learning English passive structures and dealt with the problem of passivizability of English verbs in this task. Wang Yunfeng (2002) noted in his doctor dissertation paper "L2 learning of the English passive for the Chinese learners" that "animacy of the participating arguments affects Chinese learners' acquisition of English passive structures. In the passive-felicitous context, the verb with an animate action-doer is more likely used in passive voice than the verb with an inanimate one. It is especially the case for lower and intermediate learners. However, with the development of their English proficiency, the animacy effect gradually disappears and the learners seem to be able to use almost all the passivizable verbs in passive structures including noncanonical causative verbs".

Chen Wanxia (2002) pointed out in her thesis "Acquisition of English passive voice by Chinese learners-A corpus-based approach" that "for different levels of learners, the difficulty in acquiring this grammatical item remains the same; the unaccusative hypothesis is psychologically realistic; inadequate use of passive voice is among the mistakes most likely to be made by learners. The mistakes can be attributed to the poor grasp of verb usages and the negative transfer of the mother tongue".

Liuli (2003) made a research about Chinese ESL learner's overpassivization of unaccusative verbs, made a introduction offered three explanations for the main cause, i.e., transitivization hypothesis (Yip, 1990, 1995) and NP movement hypothesis (Zoble, 1989) from syntactic structure point of view, conceptualization from pragmatic point and the overgeneralization from lexical and semantic structure point. She concluded that overpassivization is the main characteristic of Chinese learner's passive acquisition.

\section{LIMITATION ON PREVIOUS RESEARCH}

Previous studies of the SLA studies on the passive constructions did make great success and pave the way for future research. However, there are some limitations on those researcher's studies as listed below:

(1) As for the research subjects, those research do not involve native Chinese learners so as to explore the Chinese ESL learners' use of passive constructions. Even though Yip (1995) studied Chinese-speaking learners, her subjects in the research come from Taiwan. Because of the well-known reason, Taiwan's learners could not represent average Chinese learners; then the situation happened to them could not explain what would happen to the Chinese mainland learners of English. Besides, Cai (2000) conducts his study in Chinese mainland and use Chinese-speaking learners as research subject, but his subjects are only 50 English majors in PLA Foreign Language Institute, thus the findings of his research are not representative enough.

(2) In terms of research perspective, most previous researches (Zoble, 1989; Yip, 1995; Hirakawa, 1995, 2001; Oshita, 2000; Cai Jinting, 2000) merely focus on the passive unaccusative and error types, and other L2 production errors concerning passive construction are not fully explored. They do not concentrate on the other acquisition problems.

(3) In terms of research approach, only Oshita (2000) carried out a study based on the Longman Learners' Corpus, most previous researchers (Zoble, 1989; Yip, 1995; Montrul, 1999 and Cai, 2000) adopt experimental approach, devising elicited production tasks and grammaticality-judgment tasks. The number of subjects involved in the research was not large enough to represent the average learners to make more generalized and objective conclusions. 


\section{REFERENCES}

[1] Burzio, L. (1986). Italian Syntax. Dordrecht: Reidel.

[2] Ellis, R. (1999). The Study of Second Language Acquisition. Shanghai: Shanghai Foreign Language Education Press.

[3] Granger, S. (1983). The be + Past Participle Construction in Spoken English. New York: Oxford.

[4] Hirakawa, M. (2001). L2 acquisition of Japanese unaccusatives verbs. Studies in Second Language Acquisition 23: 221-245

[5] Li, C. N. \& Thompson, S. A. (1976). Subject and Topic: A New Typology of Language. In: Charles N. Li (ed.). Subject and Topic. London /New York: Academic Press, pp. 457-61.

[6] Oshita, H. (2000). What is happened may not be what appears to be happening: a corpus study of "passive" unaccusatives in L2 English. Second Language Research, 16.

[7] Perlmutter, D. (1978). Impersonal Passives and the Unaccusative Hypothesis. Proceedings of the Berkeley Linguistic Society. Berkeley: University of California.

[8] Quirk, R., Greenbaum, S., Leech, G. and Svartvik, J. (1972). A Grammar of Contemporary English. London: Longman.

[9] Selinker, L. (1992). Rediscovering Interlanguage. London: Longman.293-324.

[10] Wang, Yunfeng. (2001). L2 Learning of the English Passive. Ph.D. Dissertation. Guangzhou: Guangdong University of Foreign Studies.

[11] Yip, V. (1995). Interlanguage and Learnability from Chinese to English. Amsterdam: John Benjamins Publishing Company.

[12] Wanxia, Chen. (2002). On Acquisition of English Passive Voice from CLEC. Foreign Language Teaching and Research (3):198-202

[13] Jinting, Cai. (2000), ON Ergative of Chinese Students' Interlanguage. Foreign Language Teaching and Research (4):283-289.

[14] Xueliang, Xiong, Zhijun, Wang. (2003). Cognition on Passive Structure. Foreign Language Teaching and Research (3):195-199

[15] Wang, Yunfeng. (2001). L2 Learning of the English Passive. Ph.D. Dissertation. Guangzhou: Guangdong University of Foreign Studies.

[16] Li, liu. (2003). On the Overpassivization of unaccusative verbs in the SLA. Journal of Guangdong University of Foreign language and Trade (2):13-26.

Yuanying Wang was born in Qingdao, China in 1975. She received her M.A degree in linguistics from China Ocean University in 2008. She is currently a lecturer in the School of Foreign Languages, Qingdao University of Science and Technology, Qingdao, China. Her research interests include second language acquisition and literature. 